Faculty of Science

Faculty Publications

This is a post-review version of the following article:

Modifying Methylalumoxane via Alkyl Exchange

Harmen S. Zijlstra, Anuj Joshi, Mikko Linnolahti, Scott Collins and J. Scott McIndoe 2018

The final published version of this article can be found at:

https://doi.org/10.1039/C8DT04242]

Citation for this paper:

Zijlstra, H.S., Joshi, A., Linnolahti, M., Collins, S. \& McIndoe, J.S. (2018). Modifying Methylalumoxane via Alkyl Exchange. Dalton Transactions, 0(0), xx.

http://dx.doi.org/10.1039/C8DT04242J 


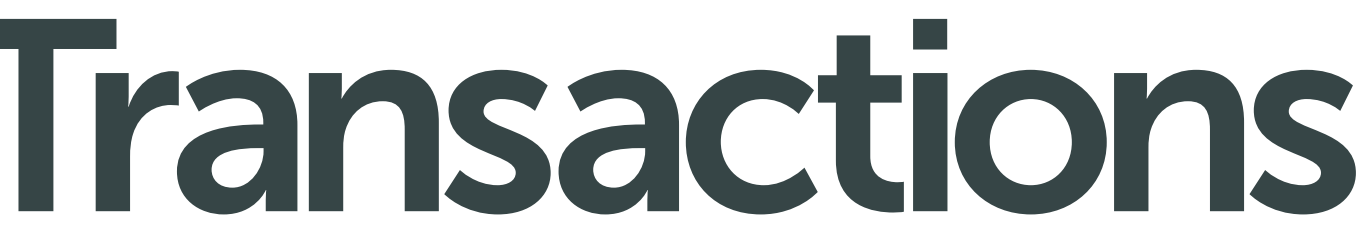

\section{Accepted Manuscript}

This article can be cited before page numbers have been issued, to do this please use: H. S. Zijlstra, A. Joshi, M. Linnolahti, S. Collins and J. S. McIndoe, Dalton Trans., 2018, DOI: 10.1039/C8DT04242J.

\section{Dalton Transactions}

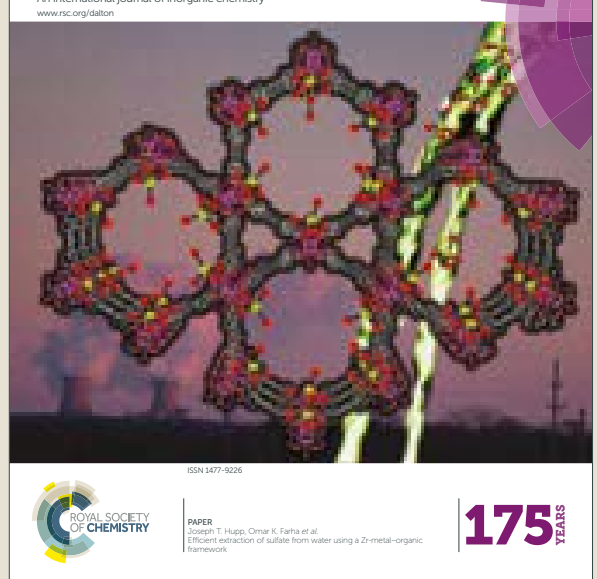

This is an Accepted Manuscript, which has been through the Royal Society of Chemistry peer review process and has been accepted for publication.

Accepted Manuscripts are published online shortly after acceptance, before technical editing, formatting and proof reading. Using this free service, authors can make their results available to the community, in citable form, before we publish the edited article. We will replace this Accepted Manuscript with the edited and formatted Advance Article as soon as it is available.

You can find more information about Accepted Manuscripts in the author guidelines.

Please note that technical editing may introduce minor changes to the text and/or graphics, which may alter content. The journal's standard Terms \& Conditions and the ethical guidelines, outlined in our author and reviewer resource centre, still apply. In no event shall the Royal Society of Chemistry be held responsible for any errors or omissions in this Accepted Manuscript or any consequences arising from the use of any information it contains. 


\title{
Modifying Methylalumoxane via Alkyl Exchange
}

Harmen S. Zijlstra, ${ }^{[a]}$ Anuj Joshi, ${ }^{[a]}$ Mikko Linnolahti, ${ }^{[b]}$ Scott Collins ${ }^{[a]}$ and J. Scott Mclndoe ${ }^{[a] *}$

[a] Department of Chemistry, University of Victoria, P. O. Box 3065 Victoria BC V8W 3V6, Canada.

[b] Department of Chemistry, University of Eastern Finland, P. O. Box 111, Fl-80101 Joensuu, Finland.

Keywords: Methylalumoxane, Activators, Aluminum Alkyls, Mass Spectrometry, Homogeneous Catalysis

\begin{abstract}
Methylalumoxane (MAO) ionizes highly selectively in the presence of octamethyltrisiloxane (OMTS) to generate $\left[\mathrm{Me}_{2} \mathrm{Al} \cdot \mathrm{OMTS}\right]^{+}\left[(\mathrm{MeAIO})_{16}\left(\mathrm{Me}_{3} \mathrm{Al}\right)_{6} \mathrm{Me}\right]^{-}$. We can take advantage of this transformation to examine the reactivity of a key component of MAO using electrospray ionization mass spectrometry (ESI-MS), and here we describe the reactivity of this pair of ions with other trialkyl aluminum $\left(\mathrm{R}_{3} \mathrm{Al}\right)$ components. Using continuous injection methods, we found $\mathrm{Et}_{3} \mathrm{Al}$ to exchange much faster and extensively at room temperature in fluorobenzene $\left(t_{1 / 2} \sim 2 \mathrm{sec}\right.$, up to 25 exchanges of Me for $\mathrm{Et})$ than $i \mathrm{Bu}_{3} \mathrm{Al}\left(t_{1 / 2} \sim 40 \mathrm{sec}\right.$, up to 11 exchanges $)$ or $\mathrm{Oct}_{3} \mathrm{Al}\left(t_{1 / 2} \sim 200 \mathrm{sec}\right.$, up to 7 exchanges). The exchanges are reversible and the methyl groups on the cation are also observed to exchange with the added $\mathrm{R}_{3} \mathrm{Al}$ species. These results point to the reactive components of MAO having a structure that deviates significantly from the cage-like motifs studied to date.
\end{abstract}

\section{Introduction}

Methylalumoxane (MAO) is an important activator for single-site, olefin polymerization catalysts. ${ }^{1}$ Its utility as a cocatalyst arises from its multiple functions: it transforms the precatalyst by alkylation and ionization, forming a weakly coordinating anion that stabilizes the active catalyst, and is an effective scavenger of trace impurities such as water and oxygen. ${ }^{2}$ Despite extensive use and decades of study MAO remains incompletely understood and its exact functioning and structure remain subject to ongoing investigations. ${ }^{3}$ The exact characteristics of this mixture vary with time and temperature making it hard to obtain concrete structural information. Its average composition, $\left(\mathrm{Me}_{1.4-1.5} \mathrm{AlO}_{0.75-0.80}\right)_{n},{ }^{4}$ molecular weight $(\mathrm{MW}, \sim 1200-2000)^{5}$ have been established 
and, in combination with computational studies ${ }^{6}$ and structurally characterized aluminoxanes ${ }^{7}$ it is generally thought that MAO is made up of cage-like structures that have the general formula $(\mathrm{MeAlO})_{\mathrm{n}}\left(\mathrm{Me}_{3} \mathrm{Al}\right)_{\mathrm{m}}$.

MAO is supplied as a solution in toluene containing a variable amount of free trimethylaluminum $\left(\mathrm{Me}_{3} \mathrm{Al}\right)$ arising from incomplete hydrolysis. The amount of excess $\mathrm{Me}_{3} \mathrm{Al}$ is known to influence polymerization catalysis and often dramatically so. ${ }^{8,9} \mathrm{Me}_{3} \mathrm{Al}$ will reversibly bind to metallocenium ions leading to both stabilization of the active species but inhibiting direct insertion into the $\mathrm{M}-\mathrm{C}$ bond, ${ }^{10}$ while efficiently participating in chain transfer reactions. ${ }^{11}$ This latter feature is undesirable for many applications, requiring physical or chemical removal of excess $\mathrm{Me}_{3} \mathrm{Al}^{8,9}$ Moreover, the use of MAO for catalyst activation requires the use of toluene due to its low solubility and stability in pure hydrocarbons. ${ }^{12}$

In attempts to develop more economical activator/scavenger combinations, higher trialkylaluminums $\left(R_{3} A l\right)$ have been used, with reduced amounts of MAO, in propene polymerization. ${ }^{13}$ In a very detailed kinetic study involving 1-hexene polymerization in hexane media, MAO, which had been previously depleted of free $\mathrm{Me}_{3} \mathrm{Al}$, was used in combination with either $\mathrm{Me}_{3} \mathrm{Al}, \mathrm{iBu}_{3} \mathrm{Al}$ or $\mathrm{nOct}_{3} \mathrm{Al}$ for catalyst activation and polymerization. ${ }^{14}$ In this case, there was no effect on polymerization rates (at constant total $\mathrm{Al}: \mathrm{Zr}$ ) but rather reduced rates of chain transfer to $\mathrm{Al}$ in the order $i \mathrm{Bu}_{3} \mathrm{Al} \sim n \mathrm{Oct}_{3} \mathrm{Al}<\mathrm{Me}_{3} \mathrm{Al}$.

MMAO prepared via non-hydrolytic routes from $\mathrm{Me}_{3} \mathrm{Al}$ and $\mathrm{R}_{3} \mathrm{Al}$ is widely used for activation and scavenging in pure hydrocarbon media. ${ }^{12}$ In comparison to MAO, the activation of metallocene or other catalysts using MMAO is not as well studied. ${ }^{1}$ MMAO or MAO that has been modified by $\mathrm{BBu}_{3} \mathrm{Al}$ is a more effective reducing agent than $\mathrm{MAO}$, and leads to the production of Zr-hydrides or $\mathrm{Zr}(\mathrm{III})$ complexes which are less active resting states or inactive, respectively. ${ }^{1 \mathrm{a}}$ In the kinetic study just discussed it was noted that extended activation times using MAO, modified by $n \mathrm{Oct}_{3} \mathrm{Al}$, resulted in a polymer featuring a bimodal MWD, resulting from more than one type of active species. ${ }^{14}$

Modification of MAO by $\mathrm{R}_{3} \mathrm{Al}$ involves alkyl exchange, forming MMAO- and $\mathrm{R}_{n} \mathrm{AlMe}_{3-n}$ - type structures. Alkyl exchange between aluminum alkyls such as $\mathrm{Me}_{3} \mathrm{Al}$ and $i \mathrm{Bu}_{3} \mathrm{Al}$ is known to be rapid. ${ }^{15}$ Studies of alkyl exchange in alumoxanes are rare but it has been shown that strained $t \mathrm{Bu}$ alumoxanes undergo facile ring opening, and alkyl exchange with $\mathrm{Me}_{3} \mathrm{Al} .^{16}$

We are not aware of attempts to establish the rate of Me exchange between $\mathrm{Me}_{3} \mathrm{Al}$ and $\mathrm{MAO}$, though separate signals for $\mathrm{Me}_{3} \mathrm{Al}$ are seen at low temperature in toluene solution by NMR spectroscopy. ${ }^{17}$ Labeled compounds such as $\mathrm{Cp}_{2} \mathrm{Zr}\left({ }^{13} \mathrm{CH}_{3}\right)_{2}$ undergo low energy scrambling reactions with both $\mathrm{Me}_{3} \mathrm{Al}$ and MAO. ${ }^{18} \mathrm{NMR} P F G-S E$ diffusion experiments on MAO and $\mathrm{Me}_{3} \mathrm{Al}$ 
suggest that the exchange of free and bound $\mathrm{Me}_{3} \mathrm{Al}$ is more rapid than the time scale $(<50 \mathrm{msec})$ of those experiments. ${ }^{19}$

We have recently shown that electrospray ionization mass spectrometry (ESI-MS) can be used to study activation of metallocene catalysts by MAO in both positive and negative ionization mode and that the data obtained can be related to polymerization experiments. ${ }^{20,21,22}$ This technique gives information about individual MAO oligomers and their reactions. ${ }^{23,24}$ When MAO is exposed to a chelating Lewis base such as octamethyltrisiloxane (OMTS) a surprisingly clean spectrum is obtained. ${ }^{23}$ Negative ion spectra of MAO and this additive show almost exclusively a species with $\mathrm{m} / \mathrm{z} 1375$ which is readily assignable as [(MeAlO) $\left.{ }_{16}\left(\mathrm{Me}_{3} \mathrm{Al}\right)_{6} \mathrm{Me}\right]^{-}$(henceforth 16,6 and containing $35 \mathrm{Me}$ groups) partnered with a $\left[\mathrm{Me}_{2} \mathrm{Al} \cdot \mathrm{OMTS}\right]^{+}$cation as seen in the positive ion spectrum. These findings support the idea that MAO may act as a source of $\left[\mathrm{Me}_{2} \mathrm{Al}\right]^{+}$during catalyst activation. ${ }^{25}$

We wondered what happens when MAO is combined with simple $R_{3} A l$ and also whether commercial MMAO could be characterized by this technique. Herein we use our previously developed, anaerobic real-time ESI-MS technique ${ }^{26}$ to probe the effect of higher $\mathrm{R}_{3} \mathrm{Al}$ species on MAO anions and gain new insights into the alkyl exchange process.

\section{Results and Discussion}

MMAO is sold under different trade names depending on the alkyl group $(3 \mathrm{~A}=i \mathrm{Bu}, 7$ and $12,=n O c t)$ and composition (3A ca. 85:15 Me:iBu, 7 ca. 85:15 Me:nOct, 12 ca. 95:5 Me:nOct). ${ }^{12}$ We investigated MMAO-12 using 5 mol\% OMTS and obtained a reasonable total ion current with $[\mathrm{Al}]=0.01 \mathrm{M}$ in fluorobenzene $(\mathrm{PhF})$. However, the negative ion mass spectrum consisted of a broad continuum of ions from $\sim 1000$ to $>3000$ Da. Expansion of the negative ion mass spectrum (see Supporting Information Figure S1) shows a multitude of signals separated in mass by $58 \mathrm{Da}$ which can be tentatively assigned based on their nominal mass. The major peaks are "normal" MAO anions, while others are present which contain one octyl group (and one less Me group). There is also evidence of anion oxidation, containing one less MAO unit than their parent anion with the composition $\left[(\mathrm{MeAlO})_{\mathrm{n}-1}\left(\mathrm{Me}_{3} \mathrm{Al}\right)_{\mathrm{m}-1}\left(\mathrm{Me}_{2} \mathrm{AlOMe}\right) \mathrm{Me}\right]^{24}$

The complex mixture of anions vs. that present in hydrolytic MAO likely reflects differences in their method of synthesis, along with random permutations of Me for nOct, possibly coupled with physical aging and/or oxidation upon prolonged storage or repackaging. On the other hand, the corresponding positive ion mass spectrum consisted of only two species $\left[\mathrm{Me}_{2} \mathrm{Al} \cdot \mathrm{OMTS}\right]^{+}(\mathrm{m} / \mathrm{z}$ 293) and $\left[\mathrm{Me}(n \mathrm{Oct}) \mathrm{Al} \cdot \mathrm{OMTS}^{+}(\mathrm{m} / \mathrm{z} 391)\right.$ in about a 98:2 ratio (see Supporting Information Figure 
S2). It thus seems that the mode of action of MMAO-12 is identical to that of MAO, though the anion distributions are different.

As the quality of the negative ion spectrum is marginal, we thus focused further work on modification of MAO by the direct addition of $\mathrm{R}_{3} \mathrm{Al}$. Addition of $i \mathrm{Bu}_{3} \mathrm{Al}$ to $\mathrm{MAO}$, either before or after ionization with OMTS, cleanly led to multiple substitution of Me for $i \mathrm{Bu}$ on the MAO anions. Depending on the amount added the extent of $i \mathrm{Bu} / \mathrm{Me}$ substitution on 16,6 could be controlled (Figure 1). 

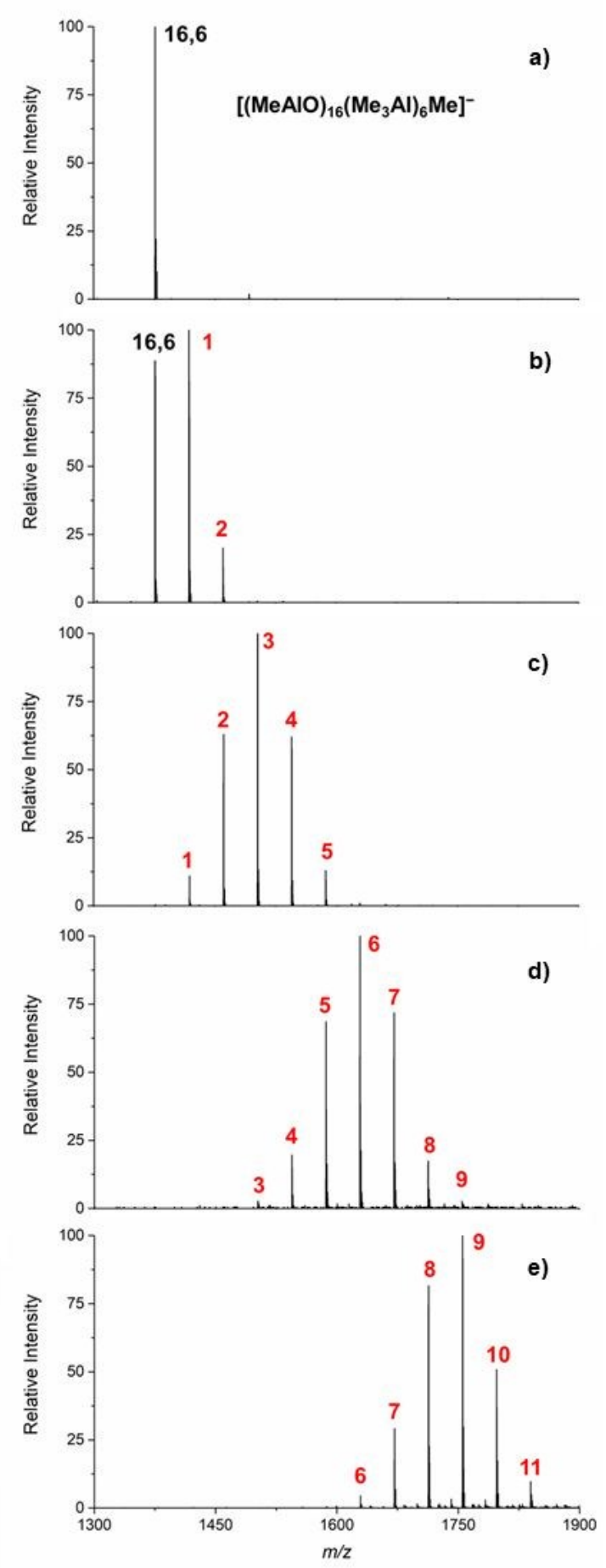

Figure 1. Room temperature negative ion ESI-MS spectra in PhF of $30 \mathrm{wt} \% \mathrm{MAO}$ at equilibrium (5 minutes after mixing), (a) modified with $1 \mathrm{~mol} \% \mathrm{BBu}_{3} \mathrm{Al}$ (b), $5 \mathrm{~mol} \% \mathrm{BBu}_{3} \mathrm{Al}$ (c), $10 \mathrm{~mol} \% \mathrm{BBu}_{3} \mathrm{Al}$ (d), $20 \mathrm{~mol} \% \mathrm{BBu}_{3} \mathrm{Al}$ (e). All at an OMTS:Al ratio of 1:100. Number of Me/iBu substitutions in $\left[(\mathrm{MeAlO})_{16}\left(\mathrm{Me}_{3} \mathrm{Al}\right)_{6} \mathrm{Me}\right]^{-}$is shown in red. 
Before addition of $i \mathrm{Bu}_{3} \mathrm{Al}$ the expected spectrum, dominated by $\mathbf{1 6 , 6}$, is obtained (Figure 1a). Addition of $1 \mathrm{~mol} \% \mathrm{BBu}_{3} \mathrm{Al}$ resulted in Me/iBu exchange as indicated by the appearance of peaks $42 \mathrm{Da}$ (the mass difference between $i \mathrm{Bu}$ and $\mathrm{Me}$ ) higher than the parent ion (Figure 1b). An equilibrium was quickly reached and the distribution remained unchanged for the remainder of the measurement. The distribution is essentially statistical, it reaches a maximum at one $i \mathrm{Bu}$ substituent and has a weighted average of $0.63 \mathrm{iBu}$ groups. Since the $30 \mathrm{wt} \% \mathrm{MAO}$ used in this study features 1.64 moles of Me groups per mole of $\mathrm{Al}$, the use of $1.0 \mathrm{~mol} \%$ of $i \mathrm{Bu}_{3} \mathrm{Al}$ with respect to $\mathrm{Al}$ corresponds to a ratio of $\mathrm{B} \mathrm{Bu} / \mathrm{Me}$ groups of $0.03 / 1.64=0.0183$ or $1.83 \mathrm{~mol} \%$. As previously mentioned 16,6 has $35 \mathrm{Me}$ groups so upon addition of $1.0 \mathrm{~mol} \%{ }_{i B u_{3}} \mathrm{Al} 0.21 \mathrm{Me}$ substitutions would be expected on a statistical basis if only one iBu group is exchanged per mole of $i \mathrm{Bu}_{3} \mathrm{Al}$ to a maximum of 0.64 if all three $i B u$ groups are equilibrated.

Addition of $5 \mathrm{~mol} \% \mathrm{BBu}_{3} \mathrm{Al}$ leads to more extensive substitution, with a weighted average of 2.90 substituted Me groups (1.07-3.20 expected, Figure 1c). Addition of more $\mathrm{BBu}_{3} \mathrm{Al}$ leads to a maximal replacement of $11 \mathrm{Me}$ groups (Figure 1d and 1e). The substitution process is reversible and upon addition of excess $\mathrm{Me}_{3} \mathrm{Al}$ to the mixture the equilibrium is pushed backwards to give a spectrum that consists principally of 16,6 with a low level of residual mono-substituted product (see Supporting Information Figure S3).

The mechanism of alkyl exchange in simple $R_{3} A l$ involves dissociation into monomeric $\mathrm{R}_{3} \mathrm{Al}$, followed by formation of mixed dimers. ${ }^{15}$ In the case of $i \mathrm{Bu}_{3} \mathrm{Al}$, which is largely dissociated, especially under these dilute conditions, exchange with MAO or the anions derived from MAO might involve dissociation of $\mathrm{Me}_{3} \mathrm{Al}$ from the latter, followed by association of $\mathrm{BBu}_{3} \mathrm{Al}$. On the other hand, anions with three $i \mathrm{Bu}$ groups are not prominent at low extents of substitution suggesting that a mixed alkyl such as $\mathrm{Me}_{2} \mathrm{AliBu}$ is involved in the exchange process, having been formed by rapid scrambling between $i \mathrm{Bu}_{3} \mathrm{Al}$ and excess $\mathrm{Me}_{3} \mathrm{Al}$ (eqn. 1).

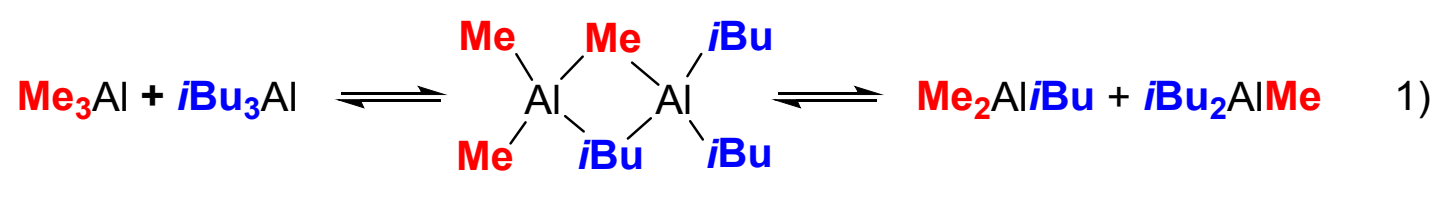

This expectation is borne out in the MS/MS fragmentation pattern which shows an overrepresented amount of $\mathrm{Me}_{2} \mathrm{AliBu}$ loss as compared to $\mathrm{Me}_{3} \mathrm{Al}$ when the ion with $\mathrm{m} / \mathrm{z} 1501$ (three $i \mathrm{Bu}$ groups) undergoes collision-induced dissociation with argon (Figure 2 and Supporting Information Figures S9-S13). The MS/MS spectrum shows that the first $\mathrm{R}_{3} \mathrm{Al}$ loss has a $\sim 45 \%$

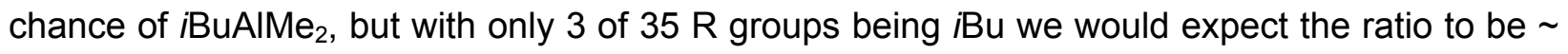


$26 \%$ (chance of an iBu loss in the first $\mathrm{R}_{3} \mathrm{Al}$ loss is $3 / 35+3 / 34+3 / 33=\sim 26 \%$ ). This indicates that bound $i \mathrm{BuAlMe}_{2}$ is especially labile compared with bound $\mathrm{Me}_{3} \mathrm{Al}$. There are no direct losses of either $i \mathrm{Bu}_{3} \mathrm{Al}$ or $\mathrm{BBu}_{2} \mathrm{AIMe}$ from the parent ion, suggesting that if those compounds are involved in the exchange, they do so with incorporation of $i \mathrm{Bu}$ groups into less labile sites of the MAO oligomer.

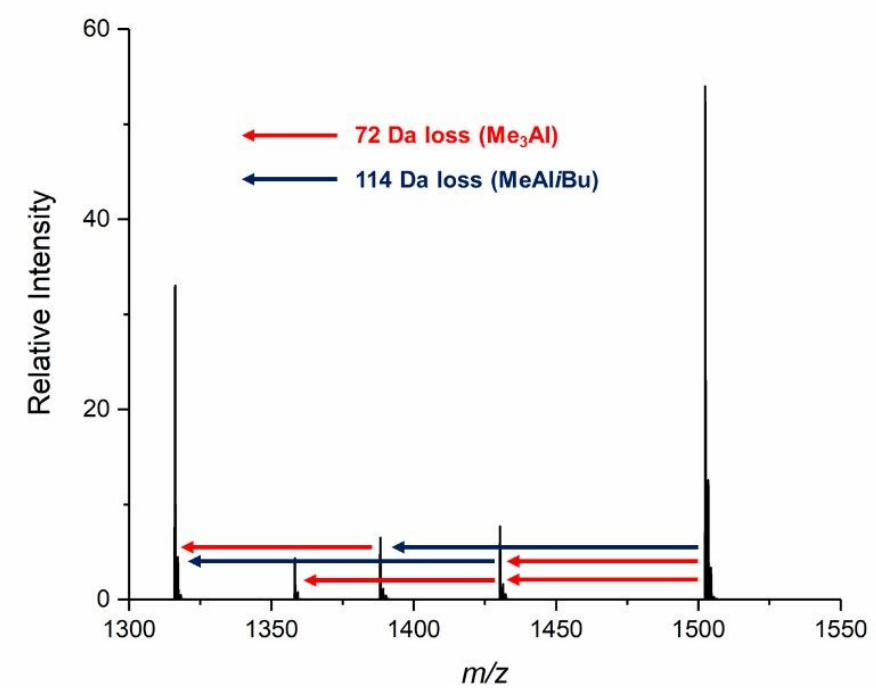

Figure 2. Partial MS/MS spectrum of the $\left[\mathrm{Me}_{32} \mathrm{BBu}_{3} \mathrm{Al}_{22} \mathrm{O}_{16}\right]^{-}$species (i.e. 16,6 after three Me for Bu exchanges) at $m / z$ 1501. Initial two losses shown only to illustrate preference for $i \mathrm{Bu}$ loss of Me for full spectrum see Supplemental Information Figure S11.

The positive ion mode spectra show a mixture of $\left[\mathrm{Me}_{n}\left(i \mathrm{Bu}_{(2-n)}\right) \mathrm{Al} \cdot \mathrm{OMTS}\right]^{+}$cations upon addition of the $i \mathrm{Bu}_{3} \mathrm{Al}$. However, unlike the corresponding negative ion spectra the order of addition of OMTS vs. iBu ${ }_{3} \mathrm{Al}$ has a pronounced effect on the appearance of the positive ion spectra (Figure 3). 

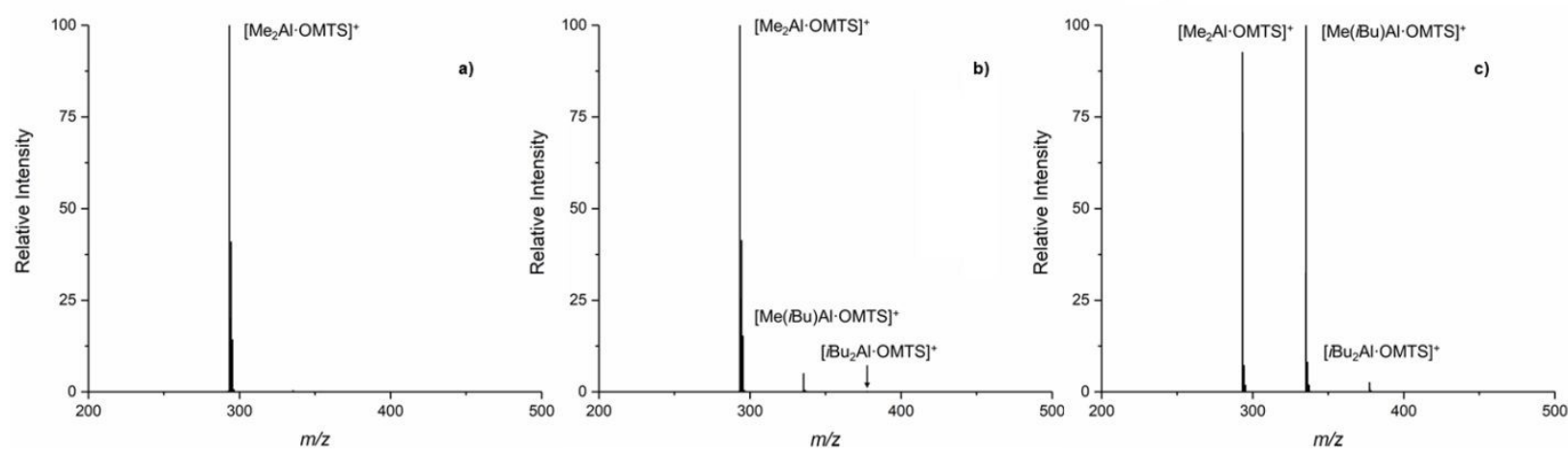

Figure 3. Positive ion spectra in PhF of 30 wt\% MAO (a), 30 wt\% MAO with $15 \% i \mathrm{Bu}_{3} \mathrm{Al}$ added after ionization (b) and $30 \mathrm{wt} \% \mathrm{MAO}$ with $15 \% \mathrm{BBu}_{3} \mathrm{Al}$ added before ionization (c). All at an OMTS:MAO ratio of 1:100.

When $15 \mathrm{~mol} \% \mathrm{BBu}_{3} \mathrm{Al}$ is added before ionization with OMTS, the main cation present is $[\mathrm{Me}(i \mathrm{Bu}) \mathrm{Al} \cdot \mathrm{OMTS}]^{+}$(Figure $3 \mathrm{c}$ ) whereas when the $i \mathrm{Bu}_{3} \mathrm{Al}$ is added after ionization, the spectrum is dominated by [Me $\left.{ }_{2} \mathrm{Al} \cdot \mathrm{OMTS}\right]^{+}$(Figure $3 \mathrm{~b}$ ). In the latter case, it is somewhat unanticipated to see any mixed alkyl cations given the chelating nature of the OMTS ligand. However, it is known that the alkyl exchange process involving $\mathrm{R}_{3} \mathrm{Al}$ does proceed in the presence of strong donors like pyridine, where rate limiting dissociation of the donor adduct is involved. ${ }^{15 b}$ Perhaps, a similar process is operative in the corresponding $\left[\mathrm{R}_{2} \mathrm{Al}\right]^{+}$cations. It is also possible that ionization of MAO is reversible, though one never observes a spectrum resembling Figure 3c. The order of OMTS addition does not change the equilibrium distribution of the anions, suggesting that alkyl exchange is equally facile between both neutral MAO and their ionized analogues.

When $i \mathrm{Bu}_{3} \mathrm{Al}$ is added first to $\mathrm{MAO}$, all labile $\mathrm{AlMe}_{n}(\mathrm{n}=1-3)$ sites are involved in the scrambling process, including those that are reactive to ion-pair formation via $\left[\mathrm{R}_{2} \mathrm{Al}\right]^{+}$abstraction when OMTS is added. In fact, at $15 \mathrm{~mol} \% \mathrm{BBu}_{3} \mathrm{Al}$ a $i \mathrm{Bu}$ :Me ratio of $0.45 / 1.64=0.274$ in the corresponding cations is expected if there is no difference in reactivity between sites substituted by $\mathrm{Me}$ vs. iBu. Figure $3 \mathrm{c}$ suggests a slightly higher ratio of ca. 0.35 indicating that there is preferential exchange at the active sites and/or that those active sites bearing an iBu group are more reactive towards $\left[\mathrm{R}_{2} \mathrm{Al}\right]^{+}$abstraction.

In an earlier paper, ${ }^{23}$ we identified two types of sites which are reactive towards $\left[\mathrm{Me}_{2} \mathrm{Al}\right]^{+}$ abstraction in structures identified as stable aluminoxane products arising from the hydrolysis of $\mathrm{Me}_{3} \mathrm{Al}{ }^{6 b}$ One of those sites is shown generically in Scheme 1, and it is obvious from its structure that it should also be prone to exchange with $\mathrm{R}_{3} \mathrm{Al}$ through loss of $\mathrm{Me}_{3} \mathrm{Al} .{ }^{15}$ 
Three isomeric structures (2-4) will result upon binding of $\mathrm{Me}_{2} \mathrm{AliBu}$, though the one with $i \mathrm{Bu}$ in the bridging position is expected to be unstable with respect to the other two. All three will interconvert through the process of alkyl exchange between bridging and terminal positions. In looking at structures 1-4, only one of these will react with OMTS to produce [Me(iBu)AI-OMTS] ${ }^{+}$. Thus, on a statistical basis (which seems probable given that exchange is essentially complete at $20 \mathrm{~mol} \% \mathrm{BBu}_{3} \mathrm{Al}$, and at $15 \mathrm{~mol}_{\%} \mathrm{BBu}_{3} \mathrm{Al}$, one expects an average labeling of 9.6 Me groups - cf. Figure $1 \mathrm{e}$ ) one would expect a ratio of $\left[\mathrm{Me}_{2} \mathrm{Al} \cdot \mathrm{OMTS}\right]:[\mathrm{Me}(i \mathrm{Bu}) \mathrm{Al} \cdot \mathrm{OMTS}]^{+}$of ca. 1:1 assuming all reactive sites are substituted by at least one $i B u$ group. The ratio of these two cations in Figure $3 c$ is close to that predicted.

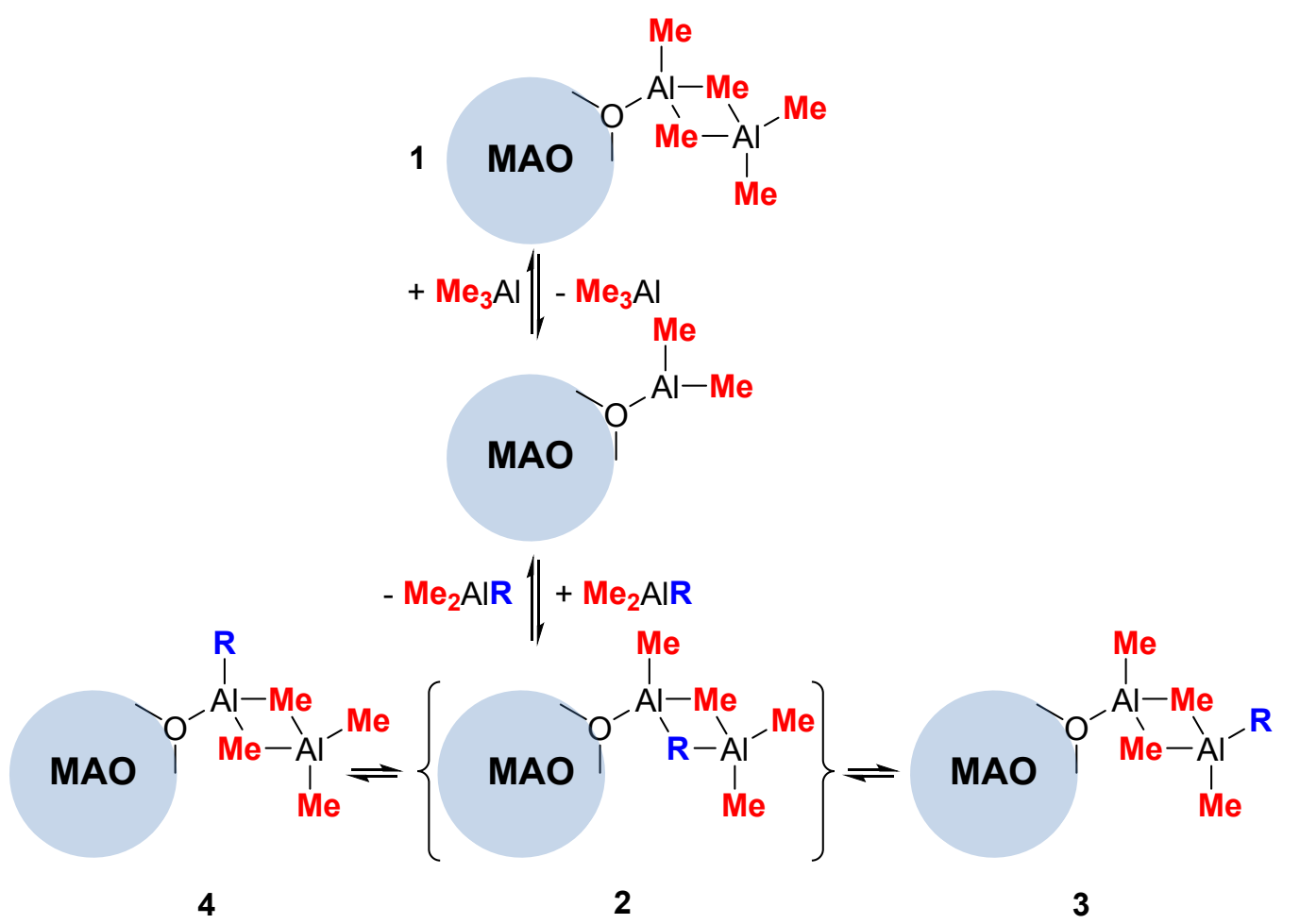

Scheme 1. Alkyl exchange between MAO and $\mathrm{Me}_{2} \mathrm{AIR}$.

Analogous structures are possible for reaction with $\mathrm{MeAliBu}_{2}$ but in this case, only two feature bridging Me groups, while of these only one can react to form $[\mathrm{Me}(\mathrm{iBu}) \mathrm{Al} \cdot \mathrm{OMTS}]^{+}$, with the other forming $\left[i \mathrm{Bu}_{2} \mathrm{Al} \cdot \mathrm{OMTS}\right]^{+}$. The latter cation is drastically under-represented on a statistical basis in Figure 3c. This suggests, as already mentioned, that $\mathrm{Bu}_{2} \mathrm{AlMe}$ may not be involved in the exchange process or that an $\mathrm{O}-(\mathrm{Me}) \mathrm{AlMe}_{2} \mathrm{AliBu}_{2}$ site is much less reactive towards ionization.

The results with $i \mathrm{Bu}_{3} \mathrm{Al}$ suggest that only limited substitution can take place (up to 11 exchanges), but the isobutyl group is significantly bulkier than the methyl group. Substitution by 
$\mathrm{Et}_{3} \mathrm{Al}$ is expected to be much more like the self-exchange process involving $\mathrm{Me}_{3} \mathrm{Al}$. Indeed, $\mathrm{Et} / \mathrm{Me}$ exchange is extremely fast and depending on the amount of $\mathrm{Et}_{3} \mathrm{Al}$ that was added, 16,6 derivatives with over $24 \mathrm{Et}$ groups could be observed (Figure 4a and S5). At the $30 \mathrm{~mol} \%$ level used, the Et/Me ratio is $0.90 / 1.64=0.55$ and thus the average level of substitution should be 19.2 vs. $\sim 20$ observed suggesting basically a statistical labeling of the MAO and the resulting anions.

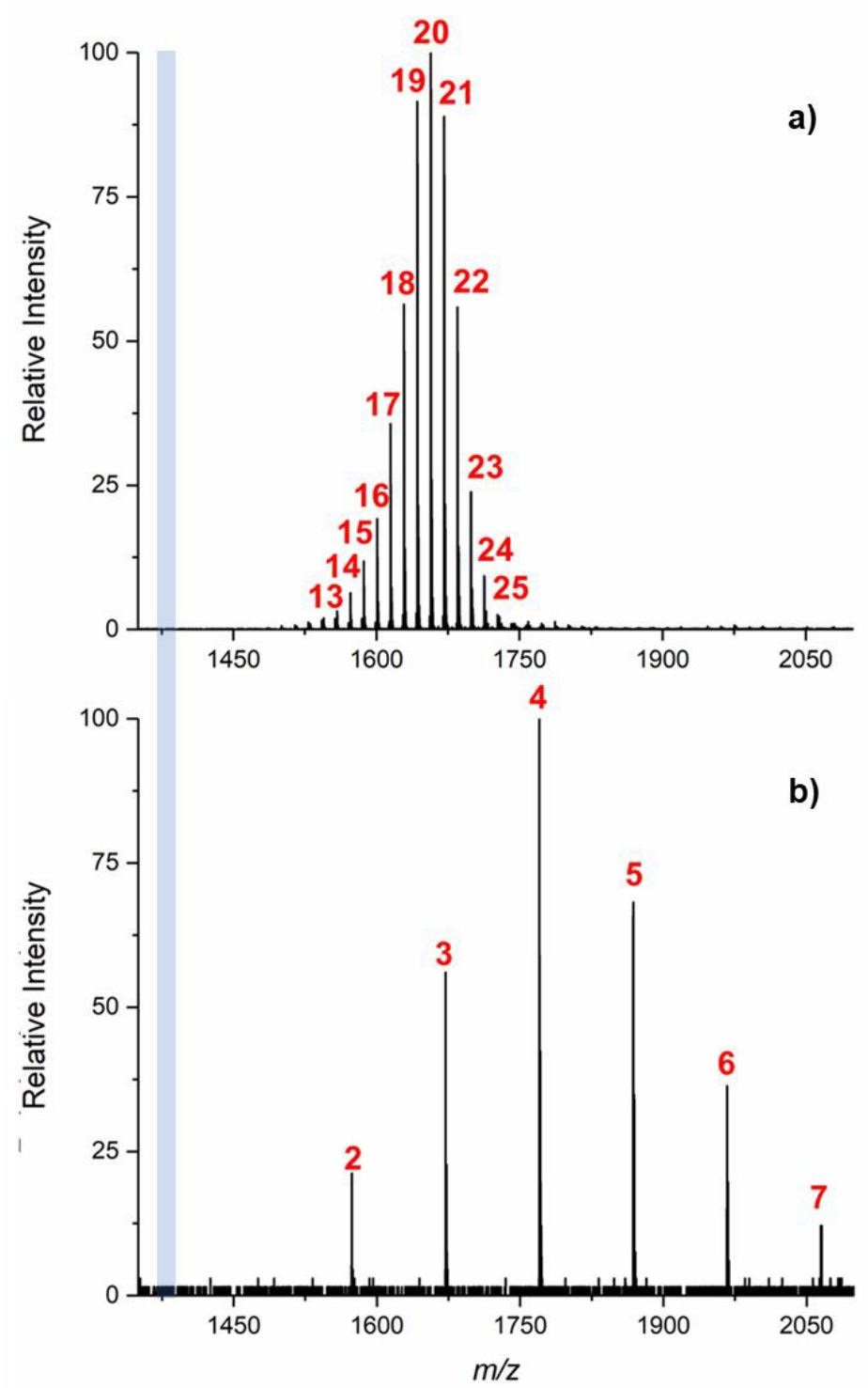

Figure 4. Negative ion ESI-MS spectra in $\mathrm{PhF}$ of $30 \mathrm{wt} \% \mathrm{MAO}$ modified with $30 \mathrm{~mol}^{\circ} \mathrm{Et}_{3} \mathrm{Al}$ (a) and $30 \mathrm{~mol} \% \mathrm{Oct}_{3} \mathrm{Al}(\mathrm{b})$. Number of Me/R substitutions in $\left[(\mathrm{MeAlO})_{16}\left(\mathrm{Me}_{3} \mathrm{Al}\right)_{6} \mathrm{Me}\right]^{-}$shown in red, blue box indicates original $m / z$ value of $\mathbf{1 6 , 6}$. 
However, at lower amounts of $\mathrm{Et}_{3} \mathrm{Al}$ the distribution is far from statistical - for example at $1 \mathrm{~mol} \% \mathrm{Et}_{3} \mathrm{Al}$ the average degree of substitution is between 2-3 Me groups vs. 0.64 Me groups for a statistical process (see Supporting Information Figure S5). It is possible that the ion-pairs are more reactive towards exchange than the neutrals in the case of $\mathrm{Et}_{3} \mathrm{Al}$ at low levels of substitution. Some evidence for this is seen in the exchange of MAO vs. the ion-pairs with $\mathrm{Me}_{2} \mathrm{AICl}$, admittedly where there is a strong driving force for substitution. ${ }^{22}$ On the other hand, MS/MS spectra reveal that loss of $\mathrm{Me}_{3} \mathrm{Al}$ is significantly more favorable than loss of $\mathrm{EtAlMe}_{2}$ from the parent ions (see Supporting Information Figures S18-21), while direct loss of e.g. $\mathrm{Et}_{3} \mathrm{Al}$ is still not observed, suggesting that binding of EtAIMe $e_{2}$ to labile sites on MAO is favored over that of $\mathrm{Me}_{3} \mathrm{Al}$, or more likely, that the Et group is rapidly scrambled into less labile sites on the MAO anions, as in structure 4 , Scheme 1.

These results point to $\mathrm{R}$ groups scrambling over the entire oligomer, meaning that the oligomer is highly dynamic with respect to exchange. The fact that the $i \mathrm{Bu}$ exchanges are more limited is probably a function of steric effects, because fitting the larger $\mathrm{R}$ groups into the oligomer becomes increasingly difficult (see Supporting Information for DFT results that support this hypothesis).

The most surprising results are obtained using $n \mathrm{Oct}_{3} \mathrm{Al}$. Despite being intermediate in steric hindrance (i.e. Et $<n O c t<i B)^{27}$ no more than 7 positions are substituted at the same 30 mol\% loading (Figure $4 \mathrm{~b}$ ). Moreover, the rate of substitution is Et $>i \mathrm{Bu}>n$ Oct (vide infra).

In comparing Figure $4 \mathrm{~b}$ with e.g. Figure $1 \mathrm{c}$ where the anion substitution level is similar, it is obvious that the signal:noise ratio for $n O c t$ anions are very much reduced compared with $i \mathrm{Bu}$. In fact, total ion counts decrease when the MAO anions are substituted by R groups in the order $\mathrm{Et}<i \mathrm{Bu}<n$ Oct at similar extents of substitution. Additionally, when monitoring substitution by pressurized sample infusion (vide infra) the more highly substituted ions are significantly less sensitively detected that those featuring lower degrees of substitution when $\mathrm{R}=n$ Oct vs. Et (see Figure S7 vs. S8). Ions containing flexible alkyl chains are known to exhibit lower ESI-MS response than rigid ions due to aggregation. ${ }^{28}$ This effect may be in play here, causing the distribution observed with nOct (Figure $4 b$ ) to not be representative of the actual degree of substitution.

To better understand the $\mathrm{R}_{3} \mathrm{Al} / \mathrm{MAO}-\mathrm{Me}$ exchange process we set out to study the reaction in real-time using pressurized sample infusion (continuous injection of solution into the mass spectrometer using a variant of cannula transfer). ${ }^{26}$ Upon addition of $1 \% \mathrm{BBu}_{3} \mathrm{Al}$ to $\mathrm{MAO}$ rapid exchange is observed resulting in the formation of the one, two, and three iBu/Me substituted 16,6 derivatives (see Supporting Information Figure S6). These species equilibrate within a minute and 
their ion counts thenceforth remain stable. Further insight into the alkyl exchange can be obtained upon addition of excess (10 mol\% with respect to total $\mathrm{Al}$ ) of $\mathrm{BBu}_{3} \mathrm{Al}$ to the MAO/OMTS mixture (Figure 5). Now a series of consecutive iBu/Me exchanges can be observed over the course of 8 minutes.

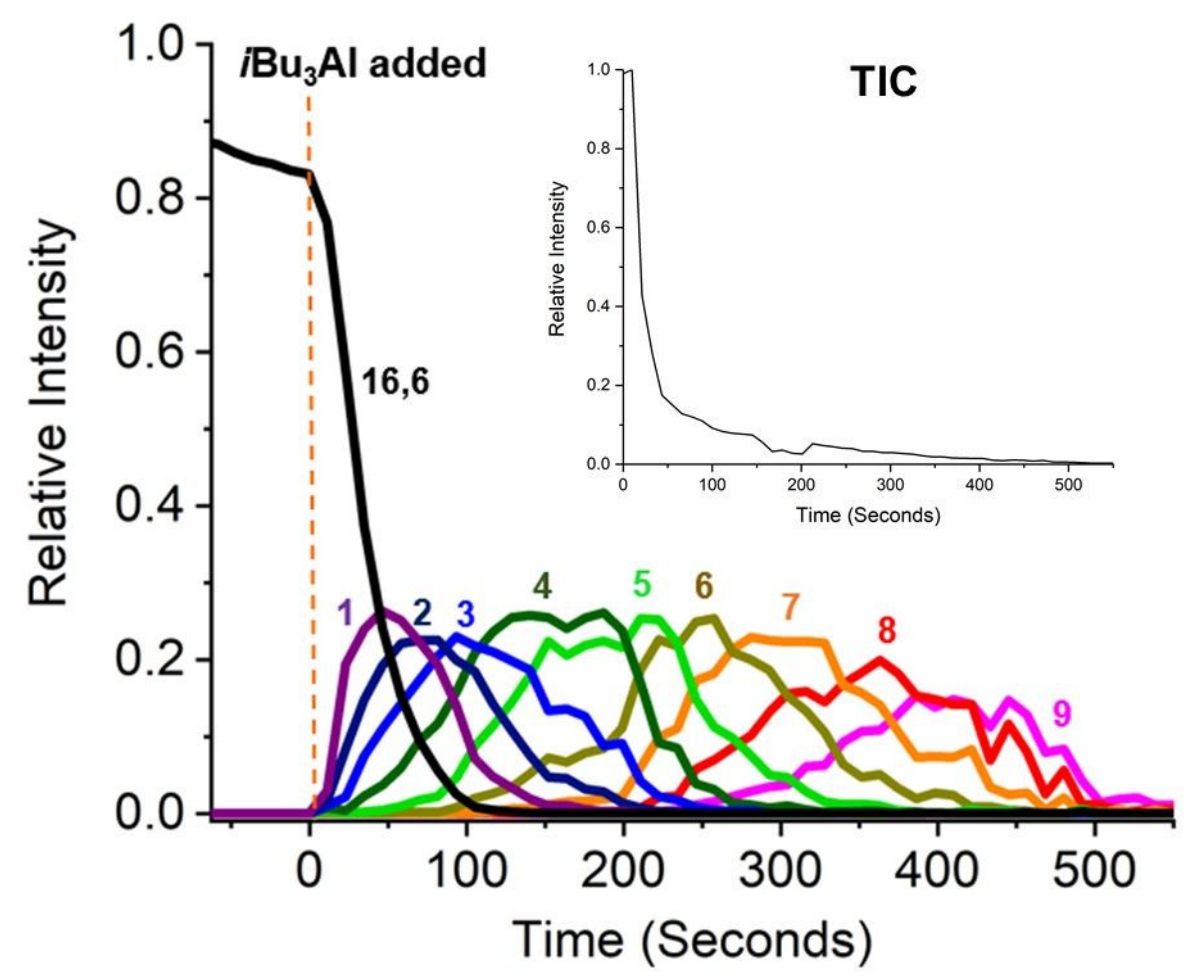

Figure 5. PSI of 10 mol\% $\mathrm{BBu}_{3} \mathrm{Al}$ modified MAO/OMTS with Al:OMTS 100:1 in PhF. Inset: total ion counts over time (TIC).

During this period the total ion chronogram (i.e. the sum of the intensities of all ions in the spectrum) shows a large decrease in intensity similar to that seen before (see Figure 5 inset). Real-time data of the addition of $\mathrm{Et}_{3} \mathrm{Al}$ and $n \mathrm{Oct}_{3} \mathrm{Al}$ to MAO/OMTS mixtures show similar trends as the $\mathrm{iBu}_{3} \mathrm{Al}$ data shown in Figure 5 (see Supplemental Information Figure S7 and S8). The speed at which the exchange takes place varies with the individual exchanges being on the second-time scale for Et $\left(t_{1 / 2} \sim 2 \mathrm{sec}\right.$ for the disappearance of 16,6), on the minute time scale for $\mathrm{iBu}\left(t_{1 / 2} \sim 40 \mathrm{sec}\right)$, and on the multi-minute time scale for $n$ Oct $\left(t_{1 / 2} \sim 200 \mathrm{sec}\right)$.

The differential rates are likely a function of at least two different factors: the extent to which the $\mathrm{R}_{6} \mathrm{Al}_{2}$ dimer is dissociated $\left(\mathrm{K}_{\mathrm{d}}=6.0,1.7 \times 10^{-3}\right.$, and $2.2 \times 10^{-5} \mathrm{M}$ for $i \mathrm{Bu}, n O c t$, and $\mathrm{Et}$ at $25^{\circ} \mathrm{C}$ in benzene), ${ }^{11,29}$ where low dissociation will lead to lower rates of exchange; and the relative rates at which monomeric $R_{3} A l$ can compete with monomeric $\mathrm{Me}_{3} \mathrm{Al}\left(\mathrm{K}_{d}=9.0 \times 10^{-8} \mathrm{M}\right)$ for occupation of 
a vacant site on the "unsaturated" MAO (i.e. 16,5; this rate will be slower for sterically encumbered $\mathrm{R}_{3} \mathrm{Al}$ ). Unfortunately, we are unable to quantitatively account for the observed differences in rate using these simple arguments. This suggests that the mechanism for exchange may well differ depending on $\mathrm{R}_{3} \mathrm{Al}$ or at least the rate determining step in the substitution process is different for Et and $n$ Oct vs. iBu in order to account for the anomalous order in the observed rates.

In earlier theoretical work, we adopted a model for the precursor to this ion-pair that was especially stable relative to other aluminoxane structures located during a systematic but targeted grid search of the reactions between $\mathrm{Me}_{3} \mathrm{Al}$ and $\mathrm{H}_{2} \mathrm{O}$. ${ }^{6 b}$ This model and the corresponding anion formed by methide abstraction, share structural features which are associated to the reactivity of MAO but are common to many other cage structures that were located during this process. As shown in Figure 6, the model for $(\mathrm{MeAlO})_{16}\left(\mathrm{Me}_{3} \mathrm{Al}\right)_{6}$ has a total of 18 methyl groups that could be considered labile, in the sense that only AI-C bonds would be broken during exchange (they are highlighted in blue). While this might account for the results seen with $i \mathrm{Bu}_{3} \mathrm{Al}$ ( 6 of these positions are bridging rather than terminal and thus disfavored - see Supporting information for DFT calculations), it falls short of the 24 low energy substitution reactions observed for $\mathrm{Et}_{3} \mathrm{Al}$.

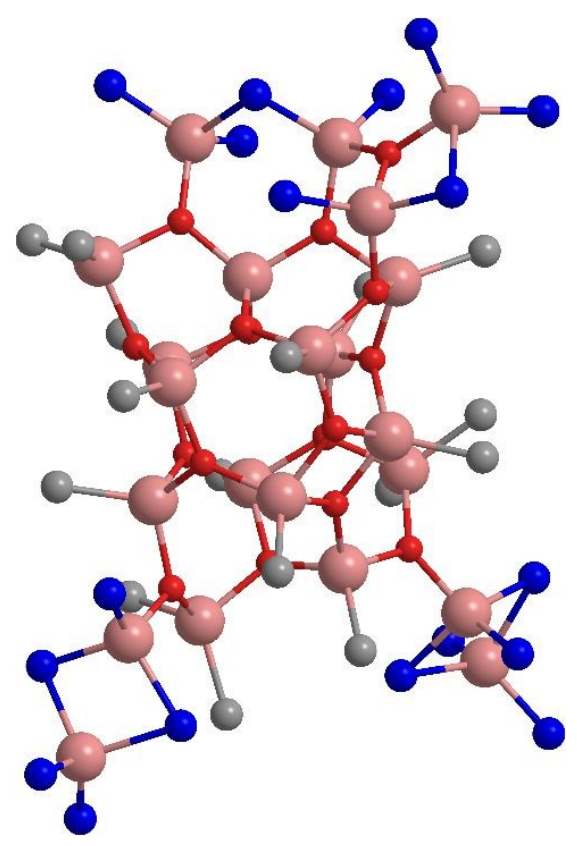

Figure 6. Optimized structure for neutral $(\mathrm{MeAlO})_{16}\left(\mathrm{Me}_{3} \mathrm{Al}\right)_{6}(\mathrm{Al}$ pink, $\mathrm{O}$ red, and $\mathrm{C}$ grey).

In order to accommodate this number of substitutions, one would have to break $\mathrm{Al}-\mathrm{O}$ bonds during the dynamic processes that interconvert $\mathrm{R}$ groups on the oligomer, and there is only one $\mathrm{Al}_{2} \mathrm{O}_{2}$ ring in this structure, with the rest being six membered, $\mathrm{Al}_{3} \mathrm{O}_{3}$ rings and thus relatively 
strain free. A similar interconverting process involving strained $\mathrm{Al}_{2} \mathrm{O}_{2}$ rings has been used by Barron et al. to explain the different isomers observed during the reaction of $(t \mathrm{BuAIO})_{6}$ with one equivalents of $\mathrm{Me}_{3} \mathrm{Al} .{ }^{16}$

Generally speaking, the most stable aluminoxane cages consist of six-membered rings, and either lack sites reactive towards $\mathrm{Me}_{3} \mathrm{Al}$ or have few sites per cage (typically less than 4) competent for methide or $\left[\mathrm{Me}_{2} \mathrm{Al}\right]^{+}$abstraction. ${ }^{6 b, c}$ We have shown here that the latter are also sites for exchange with $\mathrm{R}_{3} \mathrm{Al}$ given the present results.

Given the number of alkyl substitutions as well as their selectivity for a minor component of the mixture in the case of $\mathrm{Et}_{3} \mathrm{Al}$, the MAO activator(s) are likely to have unusual structures that depart significantly from the cage like motifs or even nanotubes that have been considered so far. We are currently investigating alternate structural motifs, which have a much higher proportion of active sites per molecule than do cages (i.e. a higher proportion of edge sites saturated with $\left.\mathrm{Me}_{3} \mathrm{Al}\right)$.

\section{Conclusions}

The selective ionization of MAO provided a unique opportunity to investigate a hitherto intractable problem: the modification of $\mathrm{MAO}$ with $\mathrm{R}_{3} \mathrm{Al}$ species. Rapid reactivity followed by statistical equilibration was observed in case of $i \mathrm{Bu}_{3} \mathrm{Al}$, and the sequential reactivity suggested that scrambling of the $\mathrm{R}_{3} \mathrm{Al}$ species with $\mathrm{Me}_{3} \mathrm{Al}$ was faster than exchange with the MAO oligomer. The extent of substitution was very high with $\mathrm{Et}_{3} \mathrm{Al}$, pointing towards exchange being facile not just for the most exposed methyl groups on the oligomer but possibly also for Me groups which are less labile by virtue of incorporation into the aluminoxane structure. These observations will spur further examination of MAO's structure by computational approaches and provide encouragement that real-time kinetic analysis of MAO reactivity is possible.

\section{Experimental}

MAO (10 and $30 \mathrm{wt} \%$ in toluene) was obtained from Albemarle and stored in the glovebox freezer upon receival. The samples were warmed to room temperature and thoroughly swirled to dissolve any precipitated content prior to use. OMTS (98\%), $\mathrm{Me}_{3} \mathrm{Al}$ (2M in toluene), $\mathrm{Et}_{3} \mathrm{Al}$ (1.9 $\mathrm{M}$ in toluene), $i \mathrm{Bu}_{3} \mathrm{Al}\left(1 \mathrm{M}\right.$ in toluene), and octyl ${ }_{3} \mathrm{Al}(0.48 \mathrm{M}$ in toluene) were purchased from Sigma-Aldrich and used as received. Fluorobenzene (Oakwood) was refluxed over $\mathrm{CaH}_{2}$, distilled under $\mathrm{N}_{2}$, and dried over molecular sieves inside a glovebox for at least 3 days prior to use.

\section{ESI-MS Details}


In a typical procedure a stock solution $(3 \mathrm{~mL})$ was prepared by dilution of MAO $(0.5 \mathrm{~mL}$ of $1.5 \mathrm{M}$ $(10 \%)$ or $0.15 \mathrm{~mL}$ of $4.6 \mathrm{M}(30 \%))$ and $0.5 \mathrm{~mL}$ of a premade PhF solution of OMTS $(0.015 \mathrm{M})$ to give a mixture with an Al:OMTS ratio of $100: 1.0 .2 \mathrm{~mL}$ of this solution was further diluted to $3 \mathrm{~mL}$ to give mixture with final $[\mathrm{Al}]$ of $0.0167 \mathrm{M}$. To this mixture varying amounts of $\mathrm{R}_{3} \mathrm{Al}(\mathrm{R}=\mathrm{Et}$, $i \mathrm{Bu}$, or octyl; for exact details see Supplemental Information) were added to give the desired MAO$\mathrm{Al}: \mathrm{R}_{3} \mathrm{Al}$ ratios. The resulting solution was injected from the glove box to a Micromass QTOF micro spectrometer via PTFE tubing (1/16" o.d., 0.005 " i.d.). Capillary voltage was set at $3000 \mathrm{~V}$ with source and desolvation gas temperature at $85^{\circ} \mathrm{C}$ and $185^{\circ} \mathrm{C}$, respectively with the desolvation gas flow at $400 \mathrm{~L} / \mathrm{h}$. MS/MS data were obtained in product ion spectra using argon as the collision gas and a voltage range of 2-100 $\mathrm{V}$.

For PSI experiments $0.4 \mathrm{~mL}$ of a MAO-OMTS solution was diluted with $6 \mathrm{~mL}$ of PhF and placed in a glass vial $(0.0167 \mathrm{M})$. The vial was attached to a rubber septum and a $178 \mu \mathrm{m}$ ID PTFE tubing was immersed in the MAO-OMTS solution, and the other end of the tubing was connected to the MS source. PSI experiments were carried out by addition of the $\mathrm{R}_{3} \mathrm{Al}$ to give the desired MAO$\mathrm{Al}: \mathrm{R}_{3} \mathrm{Al}$ ratio (for exact details see Supplemental Information).

\section{Conflicts of interest}

The authors declare no conflict of interest.

\section{Acknowledgements}

We thank NOVA Chemicals' Centre for Applied Research for financial support and useful discussions. We thank Albemarle Corp. for a kind donation of 10 and 30 wt\% MAO, and Dr. Bill Beard for helpful discussions. J.S.M. thanks NSERC (Strategic Project Grant \# 478998-15) for operational funding and CFI, BCKDF, and the University of Victoria for infrastructural support. S. C. acknowledges support for a visiting scientist position from the University of Victoria. The computations were made possible by use of the Finnish Grid Infrastructure and Finnish Grid and Cloud Infrastructure resources (urn:nbn:fi:research-infras-2016072533).

\section{References}

1. (a) M. Bochmann, Organometallics, 2010, 29, 4711-4740. (b) E. Y.-X. Chen, T. J. Marks, Chem Rev., 2000, 100, 1391-1434.

2. (a) H. S. Zijlstra, S. Harder, Eur. J. Inorg. Chem., 2015, 1, 19-43. (b) W. Kaminsky, Macromolecules, 2012, 45, 3298-3297. (c) J. N. Pédeutour, K. Radhakrishnan, H. Cramail, A. Deffieux, Macromol. Rapic. Commun., 2001, 22, 1095-1123. 
3. For recent examples see: (a) M. E. Z. Velthoen, A. Muñoz-Murillo, B. Abdelkbir, M. Cecius, S. Diefenback, B. M. Weckhuysen, Macromolecules, 2018, 51, 343-355. (b) R. Tanaka, T. Kawahara, Y. Shinto, Y. Nakayama, T. Shiono, Macromolecules, 2017, 50, 5989-5993. (c) L. Oliva, P. Oliva, N. Galdi, C. Pelecchia, L. Sian, A. Macchioni, C. Zuccaccia, Angew. Chem. Int. Ed., 2017, 56, 144227-14231. (d) L. Luo, A. Jain, J. Harlan, Abstract of papers, 253rd ACS National Meeting, 2017, INOR-1169; PMSE-126.

4. D. W. Imhoff, L. S. Simeral, S. A. Sangokoya, J. H. Peel, Organometallics, 1998, 17, 19411945.

5. L. Rocchigiani, V. Busico, A. Pastore, A. Macchioni, Dalton Trans., 2013, 42, 9104-9111.

6. See for example (a) E. Endres, H. S. Zijlstra, S. Collins, J. S. Mclndoe, M. Linnolahti, 2018, Organometallics, 2018, 37, 3936-3942. (b) M. Linnolahti, S. Collins, ChemPhysChem, 2017, 18, 3396-3374. (c) Z. Falls, N. Tymińska, E. Zurek, Macromolecules, 2014, 47, 8556-8569. (d) M. S. Kuklin, J. T. Hirvi, M. Bochmann, M. Linnolahti, Organometallics, 2015, 34, 35863597. (e) M. Linnolahti, A. Laine, T. A. Pakkanen, Chem. Eur. J., 2013, 19, 7133-7142. (f) E. Zurek, T. Ziegler, Prog. Polym. Sci., 2004, 29, 107-148.

7. (a) C. J. Harlan, S. G. Bott, A. R. Barron, J. Am. Chem. Soc., 1995, 117, 6465-6474. (b) C. J. Harlan, M. R. Mason, A. R. Barron, Organometallics, 1994, 13, 2957-2969. (c) M. R. Mason, J. M. Smith, S. G. Bott, A. R. Barron, J. Am. Chem. Soc., 1993, 115, 4971-4984.

8. V. Busico, R. Cipullo R. Pellecchia, G. Talarico, A. Razavi, Macromolecules, 2009, 42, 17891791.

9. V. Busico, R. Cipullo, F. Cutillo, N. Friederichs, S. Ronca, B. Wang, J. Am. Chem. Soc., 2003, $125,12402-12403$.

10. M. Bochmann, S. J. Lancaster, Angew. Chem. Int. Ed., 1994, 33, 1634-1637.

11. J. M. Camara, R. A. Petros, J. R. Norton, J. Am. Chem. Soc., 2011, 133, 5263-5273 and references therein.

12. D. B. Malpass "Commercially Available Metal Alkyls and Their Use in Polyolefin Catalysts" in Handbook of Transition Metal Polymerization Catalysts R. Hoff, R. T. Mathers, Eds. 2010 John Wiley \& Sons, Inc. pp 1-28.

13. R. Kleinschmidt, Y. can der Lekk, M. Reffke, G. Fink, J. Mol. Cat. A: Chem., 1990, 148, 2941.

14. F. Ghiotto, C. Pateraki, J. R. Severn, N. Friederichs, M. Bochmann, Dalton Trans., 2013, 42, 9040-9048.

15. a) E. G. Hoffman, Bull. Soc. Chim. Fr. 1963, 1467-71. b) See also Z. Černý, J. Fusek, O. Kříż, S. Heřmánek, M. Šolc, B. Čásenský, J. Organomet. Chem., 1990, 386, 157-165 for a discussion of the earlier literature.

16. M. Watanabi, C. N. McMahon, C. J. Harlan, A. R. Barron Organometallics 2001, 20, 460-467.

17. I. Tritto, M. C. Sacchi, P. Locatelli, S. X. Li, Macromol. Chem. Phys., 1996, 191, 1537-1544.

18. A. R. Siedle, R. A. Newmark, W. M. Lamanna, J. N. Schroepfer, Polyhedron, 1990, 9, 301308.

19. F. Ghiotto, C. Pateraki, J. Tanskanen, J. R. Severn, N. Luehmann A. Kusmin, J. Stellbrink, M. Linnolahti, M. Bochmann, Organometallics, 2013, 32, 3354-3362.

20. M. A. Henderson, T. Trefz, S. Collins, J. S. Mclndoe, Organometallics, 2013, 32, 2079-2083.

21. T. K. Trefs, M. A. Henderson, M. Linnolahti, S. Collins, J. S. Mclndoe, Chem. Eur. J., 2015, 21, 2980-2991.

22. S. Collins, M. Linnolahti, M. G. Zamora, H. S. Zijlstra, M. T. R. Hernández, O. Perez-Camacho, Macromolecules, 2017, 50, 8871-8884.

23. H. S. Zijlstra, M. Linnolahti, S. Collins, J. S. Mclndoe, Organometallics, 2017, 36, 1803-1809.

24. H. S. Zijlstra, S. Collins, J. S. Mclndoe, Chem. Eur. J., 2018, 24, 5506-5512.

25. L. Luo, S. A. Sangokoya, X. Wu, S. P. Diefenbach, B. Kneale, WO 2009/029857, 2009. 
26. (a) L. P. E. Yunker, R. L. Stoddard, J. S. McIndoe, J. Mass. Spectrom., 2014, 49, 1-8; (b) K. L. Vikse, J. S. McIndoe, Organometallics, 2010, 29, 6615-6618; (c) K. L. Vikse, Z. Ahmadi, J. Luo, N. van der Wal, K. Daze, N. Taylor, J. S. Mclndoe, Int. J. Mass Spectrom., 2012, 323$324,8$.

27. F. K. Cartledge, Organometallics, 1983, 2, 425-430.

28. L. D. Song, M. J. Rosen, Langmuir, 1996, 12, 1149-1153.

29. (a) M. B. Smith, J. Organomet. Chem., 1972, 46, 31-49. (b) M. B. Smith, J. Organomet. Chem., 1970, 22, 273-281. (c) M. B. Smith, J. Phys. Chem., 1967, 71, 364-370.

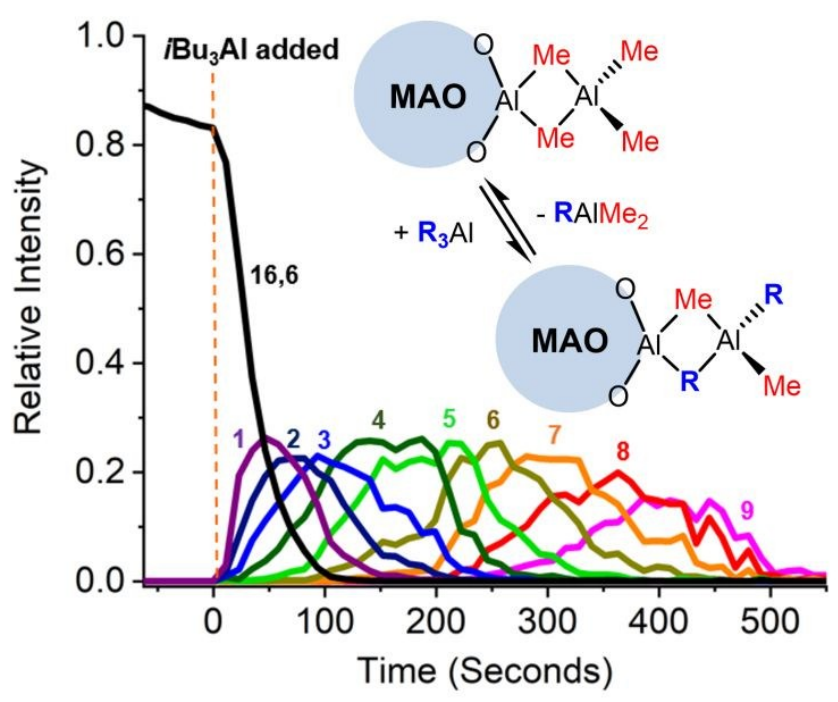

